\title{
Modelos explicativos del VIH/SIDAentre la población awajún de comunidades intervenidas por el Fondo Global en el marco de la estrategia contra el VIH
}

- Giannina Chávez

\section{Resumen}

Este artículo presenta una aproximación a los modelos explicativos sobre el VIH/SIDA que circulan entre la población awajún de comunidades que han sido intervenidas por el Fondo Global en el marco de la estrategia contra el VIH. En ese sentido, se entiende la salud como una instancia de interrelación entre el pueblo y el Estado, y por lo tanto, se tiene en cuenta que los diálogos o encuentros médicos, donde se habla de la enfermedad, son determinantes en la experiencia de la enfermedad, pues reflejan un marco de relaciones sociales determinadas histórica y políticamente.

Para ello se ha realizado trabajo de campo en el mes de febrero, agosto y setiembre del 2017 en comunidades nativas de la etnia Awajún en el río Cenepa, en Amazonas. A través de la observación constante y participante, y entrevistas abiertas y a profundidad se ha investigado cómo circula y se negocia la información con respecto al VIH/SIDA desde los distintos actores involucrados en la lucha contra el VIH, cómo el contexto sociopolítico afecta los modelos explicativos y cómo expresan su relación con el Estado. Las diversas percepciones y casos recogidos manifiestan modelos de conspiración sobre el ingreso del virus a la zona y modelos de daño y brujería, cuestionando la existencia de la enfermedad y el potencial beneficio del tratamiento. En ese sentido, se vinculan a la relación entre esta población, el Estado y el sistema de salud; así como con condiciones de pobreza y desigualdad; que llevan a la constante negociación y reinterpretación de modelos explicativos en el marco de esta estrategia.

\section{Palabras clave}

VIH/SIDA, modelos explicativos, awajún, conspiración, brujería 


\title{
Explanatory models of HIV/AIDS among the Awajún population of communities intervened by the Global Fund in the framework of the strategy against HIV
}

- Giannina Chávez

\begin{abstract}
This article presents an approach to the explanatory models on HIV/AIDS that circulate among the Awajún population of communities that have been intervened by the Global Fund stance of interrelation between the people and the within the framework of the strategy against HIV. In this sense, health is understood as an inState, and therefore, it is taken into account that medical dialogues or encounters, where this disease is discussed, are determinant in the experience of the disease, as they reflect a historical and political framework of social relations.
\end{abstract}

To this end, ethnographic fieldwork was carried out during February, August and September 2017 in native communities of the Awajún ethnic group on the Cenepa River in Amazonas. Through constant and participant observation, and open and indepth interviews, we have investigated how information about HIV/AIDS circulates and is negotiated among the different actors involved in the fight against HIV, how the socio-political context affects the explanatory models and how they express their relationship with the State. The various perceptions and cases collected manifest conspiracy models about the entry of the virus into the area and models of witchcraft, questioning the existence of the disease and the potential benefit of the treatment. In that sense, they are linked to the relationship between this ethnic group, the State and the health system; as well as with conditions of poverty and inequality; that lead to the constant negotiation and reinterpretation of explanatory models within the framework of this strategy.

\section{Keywords}

HIV/AIDS, explanatory models, awajún, conspiracy, witchcraft 


\section{Introducción}

La expansión del Virus de Inmunodeficiencia Humana/Síndrome de Inmunodeficiencia Adquirida (VIH/SIDA) es uno de los mayores problemas de salud pública a nivel mundial. De acuerdo a cifras estimadas por la ONU, actualmente hay más de 30 millones de personas afectadas por esta epidemia. Fue registrado en los ochenta y reconocido ampliamente por su naturaleza infecciosa, en particular por vías de transmisión sexual. Ante su rápido y extensivo avance en la mayoría de países del mundo, se confirmó como una epidemia, asociada además a ciertos grupos poblacionales; en particular hombres homosexuales con múltiples parejas sexuales y usuarios de drogas inyectables, quienes fueron clasificados como "grupos de riesgo" (Mazín: 2011, 88). A través de distintas estrategias y actores claves, el número de nuevas infecciones por VIH ha ido disminuyendo de manera global, pero el ritmo de esta disminución es muy diferente por regiones y por poblaciones claves.

En el Perú, la epidemia se descubrió hace 30 años aproximadamente, cuando se comenzaron a identificar los casos de SIDA en estado avanzado. En 1996, se promulgó la Ley N 26626 ("Ley CONTRASIDA") y se creó e implementó el Programa Nacional de Prevención de ETS y VIH-SIDA - PROCETSS, donde se desarrollaron intervenciones sanitarias para el control de la transmisión del VIH (sexual, vertical y parenteral) a partir del tamizaje de bancos de sangre, gestantes, atención médica a grupos con alta prevalencia e intervenciones de cambio conductual. Desde el 2004, cuando llegó el tratamiento antirretroviral (TARGA), el MINSA dirigió una intervención sanitaria para ofrecerlo de manera universal y gratuita, trabajando en conjunto con la sociedad civil e instituciones no gubernamentales, académicas y de ayuda internacional del tercer sector. Si bien estas estrategias han disminuido la mortalidad por VIH/SIDA, esta disminución se ha dado principalmente en Lima pero no en el resto del país.

En el país, hay 65 ooo personas viviendo con VIH/SIDA, en el 97\% de casos adquirido por transmisión sexual. Lima y Callao son las regiones con el mayor número de casos (70\%), seguidas por Loreto y Arequipa. Las poblaciones en mayor riesgo son los hombres que tienen sexo con hombres, las trabajadoras sexuales y la población transexual. Sin embargo, como la seroprevalencia del VIH se ha mantenido consistentemente alrededor de $0.5 \%$ en la población en general, no se considera una epidemia generalizada; sino se define como una epidemia focalizada o concentrada en ciertos grupos poblacionales considerados grupos de riesgo, localizados usualmente en las áreas urbanas de la costa y la selva peruana, donde suele ser mayor de 5\%.

Existen estudios que sugieren que algunos grupos indígenas amazónicos presentan niveles de incidencia y prevalencia mucho más altos que el nivel nacional, llegando a igualar incluso a grupos de epidemia focalizada clásicos como lo son la población transexual o los trabajadores sexuales homosexuales. A la fecha, se han detectado 8,793 y 1,259 casos de VIH y SIDA en la Amazonía peruana, respectivamente. Adicionalmente, a pesar de considerarse que existe un subregistro en los centros de salud de la población infectada, se reconoce que cada vez hay más pobladores de comunidades indígenas que viven con VIH/SIDA, especialmente entre los Awajún, Shipibos, Chayahuitas, Shawis y otros. El primer caso reportado sobre la muerte de un paciente indígena diagnosticado con SIDA se dio en mayo del 2014, en una comunidad Chayahuita; a partir del cual emergió una primera investigación epidemiológica del MINSA para determinar la prevalencia del VIH en comunidades indígenas y proveer información sobre el tema. 
Si bien hay una serie de investigaciones, sobre todo epidemiológicas, que consideran que las poblaciones indígenas tienen una mayor concentración y un mayor riesgo de expansión, hay una ausencia de estudios que investiguen a profundidad y de manera sistemática la situación actual del VIH en las comunidades indígenas (Mazín 2011: 91). Aun así, son los datos epidemiológicos los que urgen al Estado y a otros actores a buscar una respuesta a esta problemática. Hay además una serie de supuestos y prejuicios que han moldeado el abordaje el tema del VIH en pueblos indígenas, tanto desde una visión académica como desde los funcionarios públicos y el tercer sector. Estos supuestos han transformado y redefinido la relevancia política y académica del tema y la propia agenda de discusión (Nuñez, 2011: 16).

Los marcos utilizados y las estrategias tomadas nos llevan a cuestionar qué modelos explicativos están surgiendo del VIH partir de estas interacciones y en estos procesos de diálogos médicos establecidos en la intervención. ¿Cómo se negocian estos modelos? Y, por lo tanto, ¿̇en qué medida se ven permeados por el contexto sociopolítico? Esta crisis de salud pública requiere, tal como el análisis epidemiológico del Ministerio de Salud propone, nuevas y urgentes respuestas para detener y prevenir la expansión de la epidemia. En ese sentido, para lograr las estrategias de prevención necesarias, hay una necesidad de conocer, entender y reconocer los factores sociales y estructurales que llevan a la transmisión del VIH, determinantes en la expansión del virus en poblaciones más vulnerables con accesos desiguales, sociales, económicos y políticos, que van más allá de los factores de riesgo individuales. Los factores de riesgo mayores son de orden social y estructural, exceden el comportamiento individual y deben ser analizados dentro de su contexto específico para poder lograr mejores respuestas.

La bibliografía ha conceptualizado a la población indígena como un grupo de conductas de riesgo, donde se resalta constantemente la poca aceptación o el rechazo al preservativo, tanto por desconocimiento, como por falta de disponibilidad y percepciones de lo que eso puede implicar para la pareja. Además, se le da mucha importancia a ciertas conductas sexuales, como el inicio sexual temprano, las relaciones sexuales extramaritales, una alta cantidad de varones que tienen sexo con otros varones, y, en general, una cultura sexual más flexible, en especial para los hombres; como si estas fueran particulares solo de estas sociedades. Asimismo, se menciona la institución matrimonial de poliandría y el rechazo y aislamiento a las personas homosexuales, obligándolos a dejar sus comunidades exponiéndose a zonas de mayor prevalencia y situaciones de mayor riesgo. Por otro lado, se resalta mucho la falta de información o conocimiento con respecto al VIH/SIDA, tanto en el ámbito de la prevención, como de la transmisión e infección del VIH (Portocarrero 2015: 549).

Esta mirada culturalista ha guiado a las intervenciones sanitarias y ha servido de explicación y justificación de los fracasos o resultados insuficientes alcanzados. Si bien sería errado ignorar que existen distintas interpretaciones de las enfermedades como el VIH/ SIDA dependiendo del contexto y cultura en el que se den, es igual de peligroso asumir que dichas interpretaciones, concepciones y prácticas son solo un tema cultural, que propician la expansión de la epidemia. Los modelos explicativos del VIH/SIDA y los itinerarios terapéuticos a seguir, poseen un argumento de fondo, determinado a partir de situaciones y contextos que se encuentran marcados por la historia y la política. Se debe ir más allá de los elementos asociados a la dimensión cultural, debiendo investigarse a fondo dichas interpretaciones y concepciones en el marco histórico y político actual de las poblaciones afectadas. 


\section{Objetivos}

El objetivo principal de esta investigación es analizar y conocer los modelos explicativos sobre VIH/ SIDA que circulan entre la población Awajún de comunidades que han sido intervenidas por el Fondo Global en el marco de la estrategia contra el VIH. En ese sentido, se entiende la salud como una interrelación entre el pueblo y el Estado, y se considera que los diálogos médicos son determinantes en la experiencia e interpretación de la enfermedad, pues reflejan y se dan dentro de un marco de relaciones sociales determinadas histórica y políticamente. Por lo tanto, los modelos explicativos que se han investigado se dan dentro de un contexto sociopolítico, histórico y económico determinado que ha permitido hacer un análisis etnográfico a través de los diálogos y sistemas médicos involucrados.

Para ello, la investigación ha buscado analizar cómo circula y se negocia la información con respecto al VIH/SIDA desde los distintos actores involucrados en el marco de la lucha contra el VIH, cómo afecta el contexto sociopolítico awajún a los modelos explicativos sobre el VIH/SIDA y cómo expresan su relación con el Estado.

\section{Situación actual}

De acuerdo al INEI, las comunidades nativas amazónicas ocupan alrededor del 50\% del territorio de Amazonas, con una población de aproximadamente 52 mil habitantes, casi un $14 \%$ de la población total del departamento. Casi 16 mil son población Awajún, habitantes del distrito del Cenepa, en la provincia de Condorcanqui, donde parece desarrollarse con mayor intensidad la epidemia.

Al 2015, se habían reportado 747 casos de VIH y 183 de SIDA, en la región de Amazonas; 311 y 69, respectivamente, fueron de la provincia de Condorcanqui, zona mayoritariamente indígena. Son las comunidades de esta cuenca, en los alrededores de Bagua y los distritos del Cenepa y Santiago, las más afectadas. Es importante señalar que el número de personas con VIH/ SIDA también se ha incrementado porque las pruebas de tamizaje se vienen aplicando en más comunidades, para dimensionar verdaderamente el problema y efectuar un oportuno diagnóstico, aunque es casi imposible mantener un registro actualizado y real de la situación.

Según los datos de UNICEF (2014), en el 2007 se registró el primer caso en comunidades awajún del Cenepa, y entre ese año y el 2014, se registraron 72 casos de personas infectadas de VIH en los centros de salud de la Red de Condorcanqui (Huampami, Kusu Kubaim, Kusu Pagata, Achu y Alto Canampa). De estos casos, la mayoría son hombres jóvenes, entre los 18 y 29 años, y, en menor porcentaje, mujeres en el mismo rango de edad. El $44 \%$ de las personas afectadas en este periodo han fallecido, 32 muertes que se suelen atribuir a la poca accesibilidad al TARGA como tratamiento periódico de cuidado (solo el 6\% del total de infectados recibió TARGA) y a la ausencia de una estrategia comunicacional intercultural sobre el VIH/SIDA.

El acceso a tratamiento del distrito Cenepa se centra en la Micro Red de Salud de Huampami, que funciona como punto estratégico. Sin embargo, el traslado de los pacientes de las comunidades más alejadas les significan gastos superiores a los que pueden manejar. Los que sí acceden al tratamiento suelen hacerlo por encontrarse en comunidades más cercanas o por la gestión de otros actores estratégicos que ayudan a reducir los costos. "Estas comunidades tienen dificultades en la accesibilidad al C.S 
tanto por el transporte terrestre o fluvial requerido, como por los costos que estos traslados implican, lo cual se dificulta por su condición de pobreza extrema, existiendo familias que no llegan a acudir al C.S ni a ser visitadas por estos factores." (Portocarrero: 2016). Por otro lado, se ha determinado que el mayor foco de contagio dentro de esta población son los jóvenes, quienes no están priorizados dentro de la NTS como población clave para el tratamiento contra el VIH/SIDA. Un 24\% del total de la población infectada en Condorcanqui son hombres homosexuales entre los 15 y 25 años (UNICEF 2004: 31).

En este contexto, se han comenzado a desarrollar ciertas estrategias de prevención y tratamiento de VIH y otras ITS, con un enfoque intercultural; como, por ejemplo, capacitar en el idioma e intentar utilizar y hablar en los marcos interpretativos de la población. Sin embargo, este proceso de supuesta horizontalidad ha sido en realidad visto como unilateral, pues las dinámicas participativas no han logrado tener en cuenta aquello que se busca desde la población misma, sus organizaciones e instituciones, así como su propia respuesta al tema. Adicionalmente, en el caso Awajún, ha habido una mayor cantidad de casos con un fuerte componente político, dado que son casos que se han desarrollado en contextos de conflicto y zonas en grandes procesos de transformación.

La intervención del Fondo Global se ha dividido en dos estrategias principales, contando ambas con un carácter de pertinencia cultural. Por un lado, la estrategia comunicacional del VIH, las capacitaciones, talleres y otras actividades de concientización y comunicación sobre esta epidemia, estrategia encargada a la ONG Salud Sin Límites. Por el otro lado, las brigadas de tamizaje y atención, responsables de identificar casos, promover las pruebas rápidas y asegurar que aquellos casos positivos inicien y sigan el tratamiento, de lo cual se ha encargado la ONG Path Finder.

\section{Metodología: Lugar, población y técnicas}

El trabajo de campo de esta investigación se realizó en el Centro Poblado Huampami, en el distrito El Cenepa, provincia de Condorcanqui, región Amazonas. La primera visita fue en febrero del 2017, para realizar una aproximación inicial. Luego, se realizaron 2 meses de trabajo de campo desde agosto hasta inicios de octubre del presente año. Huampami fue elegido por ser la capital del distrito y, por lo tanto, Micro Red de la Red de Salud de Condorcanqui, por lo que cuenta con un centro de salud bien equipado, mayor cantidad de personal y mejor infraestructura que la de los puestos de salud, equipo de tratamiento antirretroviral (TARGA) e, incluso, un laboratorio de análisis y pruebas de tamizaje, que lo vuelve importante para las comunidades cercanas. Asimismo, por ser un espacio esencial de la intervención del Fondo Global contra el VIH/SIDA al ser una de las zonas con mayor cantidad de casos de VIH/SIDA y estar siendo utilizado como modelo de referencia del Estado para diseñar la estrategia a seguir contra el VIH en poblaciones indígenas. Este espacio, si bien no es el único, ha sido central para explorar los diversos escenarios de diálogos médicos.

Los datos recolectados han sido obtenidos en entrevistas abiertas a profundidad y observación constante y participante en diversos ámbitos de la comunidad y del centro de salud. Se han observado en el centro de salud las interacciones entre la población y el personal, así como entre el personal técnico awajún y el mestizo. Se hizo también un acompañamiento de atenciones extramurales de vacunación, control de crecimiento y seguimiento de pacientes con VIH/SIDA, que permitieron reconocer los discursos locales y las respuestas de la población, así como las condiciones de vida, 
vivienda, alimentación y consumo. Todos estos eventos fueron grabados y transcritos en un cuaderno de campo, para identificar los elementos relevantes y revisitarlos, a través de las entrevistas y conversaciones futuras. Asimismo, se han observado eventos específicos de la intervención del Fondo Global y de la comunidad, entre ellos, las capacitaciones de VIH/SIDA realizadas en el centro de salud a diversos actores, los seguimientos a pacientes en distintas comunidades y las interacciones entre el personal de salud y los pobladores. Hay que tener en cuenta que un diálogo médico no necesariamente implica solo una mirada profesional, sino un espacio donde actores interpreten, hablen y expliquen la enfermedad desde sus diversos discursos y posiciones.

Los interlocutores de esta investigación son pertenecientes a la etnia awajún y mestizos de otros departamentos del Perú, que habitan en las comunidadesv Huampami, San Antonio, Suwa Pangki y Mamayaque; ubicadas a cuatro horas de la ciudad de Nieva por navegación fluvial en el río Cenepa, en Condorcanqui. Todas las comunidades y sus respectivos puestos de salud están bajo la jurisdicción de la Micro Red de Huampami, que, a su vez, es jurisdicción de la Red de Salud de Condorcanqui, ubicada en Santa María de Nieva. Las entrevistas y conversaciones se realizaron con autoridades de la comunidad, personal de salud y de las intervenciones awajún y mestizo, docentes y adultos pobladores de la zona. La investigación ha sido llevada a cabo dentro de patrones éticos, así como con el consentimiento de las autoridades y personal local, prometiendo confidencialidad y anonimato de los participantes.

\section{Resultados}

Al investigar los modelos explicativos circulantes sobre el VIH/SIDA, surgieron dos grandes ramas de interpretación. La primera podría ser englobada bajo el concepto de teorías de conspiración; la segunda, muy utilizada y recurrente en contextos de VIH en sociedades poscoloniales africanas, estaría compuesta por todos los relatos que entrarían en la teoría del daño, o más específicamente, brujería.

El primer grupo o las teorías de conspiración se refieren a relatos recolectados sobre el ingreso y origen del VIH a la zona, de tal modo hacen referencia a un aspecto más abstracto de la enfermedad. Existe todo un repertorio de teorías que proponen que el virus ha sido traído por agentes foráneos para la exterminación de la población indígena y, en particular, de la población awajún. Estas historias contienen diversos medios por los que el virus ha ingresado, así como diversos agentes que se han encargado de dicho ingreso; sin embargo, todas coinciden en que el motivo general es eliminar al pueblo awajún. De los relatos recopilados, los agentes varían desde algo tan general como los mestizos (apach) o el Estado, hasta los mineros, el personal de salud, los policías, llegando a ser tan específico como los familiares del mayor Bazán desaparecido en el Baguazo. Estos actores estarían utilizando diversos medios para que el virus ingrese a la zona: mediante la inyección del virus en los mangos, plátanos y pollos que la población va a consumir, así como en los propios enlatados de Qali Warma que manda el Estado; a través de las vacunas y los exámenes de laboratorio -donde, en vez de tamizar para una prueba positiva o negativa, se inyectaría el virus a la persona- y los propios anticonceptivos, con el propósito adicional de esterilizar a las mujeres indígenas para que no se reproduzcan más. Eliminar a la población o lograr que ya no se reproduzcan más, tendría dos motivos ulteriores: quedarse con el territorio que los awajún estarían "mezquinando" para la extracción de minerales y otros recursos naturales, y como represalia del Estado por el Baguazo y la participación de este pueblo en él. Para analizar qué hay detrás de esta teoría social y genocida de la epidemia, es necesaria la comprensión de las lógicas sociales e históricas previas de esta población. 
El segundo conjunto de relatos recolectados tendría un enfoque más concreto pues no intenta explicar el ingreso de la epidemia en la zona o la población, sino que plantea la causa del VIH o sus síntomas en una persona específica. Aparece la teoría del daño como razón de las muertes y los enfermos de síntomas de SIDA, en contraposición a las explicaciones del sistema oficial. De acuerdo a la investigación realizada por UNICEF, los mensajes emitidos desde el MINSA y la DIRESA sobre el VIH/SIDA no son una explicación lógica para las comunidades awajún; mientras que la teoría del daño es más comprensible (2014:12). Al hablar de los casos en concreto, parece ser que el modelo más constante es la brujería o Waweamu, dado que hay una serie de cuestionamientos a la propia existencia de la enfermedad. Entre ellos porque, como es una enfermedad nueva y desconocida para la zona, se busca entender su origen y causas dentro de los modelos de referencia previos; por otro lado, la asintomatología del virus - dado que hay un largo período de tiempo donde uno puede ser portador del virus sin manifestar síntomas, los que pueden presentarse de un día a otro y empeorar rápidamente- los hace poner en duda su existencia así como la necesidad del tratamiento. Otra de las razones son las inexactitudes y contradicciones en los exámenes. Los primeros en realizarse son dos pruebas rápidas con solo una gota de sangre, que pueden ser hechos en la micro red o en los centros de salud; sin embargo, el confirmatorio es un examen de laboratorio que se envía al INS en Lima y cuyos resultados se obtienen luego de 6 meses, despertando muchas dudas con respecto a exámenes que no concuerdan, falsos positivos o negativos, además de pérdida total de interés en un diagnóstico correcto por la demora. Además de las contradicciones que los pobladores encuentran sobre casos de VIH, donde padres positivos no han contagiado a sus hijos, o esposos no han contagiado a sus parejas. Este segundo conjunto afecta el itinerario terapéutico, pues si el paciente o sus familiares consideran que se trata de daño o brujería, se buscará solucionar el malestar con plantas, principalmente, la catahua y el toé, dejando de lado el tratamiento antirretroviral o TARGA.

Ambos grupos de relatos y modelos explicativos son constantemente negociados y circulan a través de diversos actores con distinta información. Esto crea un escenario de incertidumbre y ambigüedad en los argumentos, pues no hay la certeza de que uno sea correcto ni siquiera por los propios pobladores. Muchos de estos relatos son rumores que van interpretándose y reinterpretándose de acuerdo al momento $\mathrm{y}$ al actor que los escucha y que luego vuelve a relatar. Asimismo, ambos grupos de explicaciones han sido relatados en tercera persona, desligándose el interlocutor de la responsabilidad de la explicación. Se han escuchado frases como "mis paisanos creen", "la gente piensa", o "han dicho", sin adjudicárselas directamente.

Para entender estos modelos explicativos y las distintas negociaciones y reinterpretaciones a la que son sometidas, es importante comprender el contexto sociopolítico de la zona y la población, así como sus aspectos socioeconómicos. Tanto Huampami como toda la zona del Cenepa son zonas de extrema pobreza, con acceso mínimo a servicios y condiciones básicas. Las comunidades cuentan con servicio de agua, mas no de desagüe -con excepción de una zona céntrica en Huampami-, y con energía eléctrica producida a altos costos por un motor a gasolina. La dieta alimenticia es extremadamente pobre y poco variada, por lo que tienen un altísimo índice de desnutrición y anemia. El acceso a la salud es también muy precario. Existe mucha inequidad de género ya que la mujer cumple un rol subordinado. El comportamiento de los varones hacia ellas es muy sexualizado y puede llegar a ser bastante violento. La población awajún de la zona vive en un contexto de "violencia estructural" (Farmer, 1997), es decir, una violencia histórica, social y de género. "La violencia que se ejerce 
contra los pobres encuentra sus fundamentos en las fuerzas históricas, muchas veces forjadas por procesos económicos. Estos procesos y estas fuerzas constituyen la base de la 'violencia estructural', una violencia de intensidad constante que puede tomar varias formas: racismo, sexismo, violencia política, pobreza y otras desigualdades sociales. A través de la rutina, del ritual o de las transcursos difíciles de la vida, esta violencia estructural pesa sobre la capacidad de las personas para tomar decisiones sobre sus vidas" (Farmer, 2003).

Este nivel estructural de violencia y este contexto de pobreza es una de las razones por las que cuestionamos uno de los principales argumentos culturalistas que pretende explicar la expansión de la epidemia clasificando a la población como extremadamente promiscua, como condición inherente de la sexualidad indígena, en particular amazónica, estigmatizando así a la población, dejando de lado otras condiciones que nutren la epidemia y promoviendo intervenciones moralistas en base a prejuicios, en vez de concentrarse en la violencia estructural en la que viven estas personas. Muchas de estas situaciones de "promiscuidad" se dan en jóvenes mujeres o varones que, ante su condición de pobreza, no ven otra posibilidad que la de vender su cuerpo e intercambiar relaciones sexuales o algún tipo de tocamiento por un plato de comida, alguna golosina o ropa, o por una compensación no mayor a cinco soles. La libertad sexual no es que te paguen por tener sexo; no hay nada libre en condicionar tu "consenso" a un dinero que necesitas para sobrevivir.

En este contexto de violencia estructural, dado que el Baguazo es un evento crucial que ha marcado también a esta población y que aparece recurrentemente en sus relatos, hacer una revisión de la historia y el contexto sociopolítico del pueblo awajún, en particular su relación con el Estado permite ver, por un lado, al Estado peruano con un historial de modelo extractivista que permea las políticas y donde los derechos territoriales de los pueblos indígenas son promovidos con desdén; y, por el otro, la oposición del pueblo awajún hacia la minería en la Cordillera del Cóndor a través de diversos mecanismos nacionales y regionales, siendo el Baguazo el evento crítico que polarizó totalmente estos lados. Los oídos sordos del Estado ante las demandas de las organizaciones indígenas demuestran su interés por beneficiar a las empresas mineras, poniendo en riesgo los territorios y derechos de estos pueblos en aras de un modelo no sostenible y basado en la ampliación de la exploración petrolera (Barclay, 2009: 10). En ese sentido, hay que considerar también que en su relación con el Estado, no son solo los territorios lo que estas poblaciones defienden, sino su "propia identidad colectiva étnica: de pensarse como parte de una historia propia asociada a un territorio específico que les pertenece" (Araujo: 2016).

Por lo tanto, queda claro que este y otros hechos históricos han dejado su marca en la población, volviendo la relación con el Estado y la sociedad mayor más tensa y definitivamente más desconfiada y temerosa. Esta relación no solo se expresa de manera abstracta, sino en la propia negociación con el sector salud y su personal. La desconfianza viene de ambos lados: el personal, usualmente mestizo, ha llegado a ser acusado de brujería o de inyectar el virus en las agujas de laboratorio; aunque se les tiene un poco más de confianza a los técnicos awajún parte del personal, se miran con recelo algunas de sus actitudes y comportamientos; la población teme las intervenciones como la cesárea, absolutamente necesaria para evitar la transmisión vertical de madre a hijo, por miedo a la esterilización y a la anestesia; las condiciones del sector salud en la zona no ayudan a instaurar una relación de mayor confianza: hay escasez de medicamentos, incluso de guantes; una constante rotación del personal y, muchas veces, las referencias para emergencias suelen complicarse por falta de gasolina para el transporte, o luz para ecografías u otros exámenes. Por el 
otro lado, el personal de salud y los miembros de las intervenciones sanitarias cargan también con una cultura, un conjunto de valores, creencias, prácticas y argumentos en los que han sido socializados y de los que difícilmente pueden despojarse, lo que a veces les ocasiona miedo y desconfianza de sus propios pacientes, especialmente, en el caso del VIH donde el tema del contagio es una amenaza latente.

\section{Conclusiones}

Una vez más resaltamos la necesidad de trascender un enfoque de esencialismo culturalista y exoticismo conductual, que ignora la incorporación de la historia y las relaciones raciales, de género, clase y generacionales de la población. Consideramos que es un enfoque injusto y poco efectivo, que termina por responsabilizar de la aflicción a la población, y en donde se presentan sus creencias y conductas como el mayor obstáculo para luchar contra la epidemia. Pareciera ser que este tipo de explicación implica que el resultado es inevitable y que la población está condenada por la debilidad de sus normas morales, perdiéndose la posibilidad de otra explicación y produciéndose una representación imaginaria de la sexualidad awajún y una imagen descontextualizada y ahistórica de los awajún y su comportamiento sexual (Fassin, 2007: 151). Incluso, la teoría del daño y brujería no debe ser planteada como encerrada en la tradición, las creencias y la magia. Presentar estas creencias como el mayor obstáculo trae implícito el que los elementos sociales, económicos y étnicos se dejen de lado. Es posible analizar la brujería desde un enfoque menos culturalista que permita inscribirla en dinámicas sociales y políticas, que expresan la memoria de esta población (Fassin, 2007: 93). Verla como razón de expansión u obstáculo de prevención y tratamiento instala una serie de prejuicios y estereotipos.

Tal como Fassin propone para el caso africano, el VIH se ha vuelto una "epidemia de disputas", donde encontramos dos tipos de economías: una del "resentimiento" donde el pasado constituye un reservorio de memorias dolorosas, y otra de la "sospecha" donde el presente es interpretado a través de un lente de desconfianza hacia cualquiera con una posición de autoridad (Fassin, 2007: 170-171). La epidemia, por tanto, es una experiencia que renueva un pasado de discriminación y violencia, de ser considerados ciudadanos de segunda categoría; y, a la vez, esparce dudas y desconfianza sobre su realidad y sobre sus especialistas. En ese sentido, las teorías de conspiración son una representación de hostilidad étnica que revela conflictos de la historia no resueltos como lo es el Baguazo. Dichas teorías tienen menos que ver con la coherencia y significado que con el poder y la contestación, que permiten entender la realidad. De tal forma, la epidemia del VIH revela realidades invisibles del mundo social, prejuicios, tensiones y relaciones de poder que existen pero que no se perciben; y esas realidades son incuestionablemente políticas (Fassin, 2007: 17). Para ello, hay que también entender que las políticas de salud no son solo sobre salud, son un tema político; por lo tanto, el VIH también lo es. La guerra semántica es más que una confrontación entre modelos explicativos, es una confrontación entre mundos, maneras de relacionarse a la historia y la memoria, y definiciones de moral y política (Fassin, 2007: 33).

Es importante entender el VIH en relación al cuerpo y la memoria, pues permite ver cómo la historia se inscribe en el cuerpo, y cómo se le da sentido al presente a través del pasado. En ese sentido, "requiere pensar sobre la humanidad compartida menos en términos de diferencia que de desigualdad, menos como un asunto de cultura que de historia” (Fassin, 2007: XV). 
Se propone realizar una antropología política del VIH, que tome en serio todo el conjunto de actores y argumentos de esta crisis para tratar de hacer que sus posiciones sean inteligibles por todos. Es necesario reconocer que el objeto de controversia no es una pregunta de qué modelo o teoría es verdadera y cuál es falsa, como las discusiones médicas usualmente dicen. Es importante ver que no se puede construir una política de salud, o una democracia, simplificando hechos, rechazando críticas y finalmente negando la historia.

Ver los problemas de salud sólo desde una perspectiva médica limita los factores que podrían ayudar a la sostenibilidad de intervenciones y estrategias. Las posibilidades de ser infectado y la duración de la sobrevivencia están íntimamente relacionados al ambiente humano y material en el que vive la población, por lo que realizar acciones que mejoren las condiciones de vida y las inequidades económicas y políticas puede ser tan importante para la sobrevivencia de pacientes pobres como administrar la droga antirretroviral; además de no ser mutuamente exclusivos, como el debate suele posicionarlos. No basta con considerar que es solo la ausencia de información correcta y biomédica la que hace falta en la población indígena amazónica para poder detener y prevenir la expansión de esta epidemia, sino, tal vez, lo que se necesita primero es una reconciliación del Estado peruano con la población indígena, en este caso, awajún.

\section{BIBLIOGRAFÍA}

Alva, I. (2012).

Social and contextual factors that influence HIV risk behaviors among indigenous MSM in the Peruvian Amazon. Retrovirology, 9(1), 112.

Araujo, A. L. (2016).

Entre campañas y vueltas: las elecciones presidenciales de Nosotros los awajún. Argumentos 3 .

Baer, H. A., Singer, M., \& Susser, I. (2013).

Medical Anthropology and the World System: Critical Perspectives (3rd ed.). California: PRAEGER.

Bartlett, E., Zavaleta, C., Fernández, C., Rázuri, H., Vilcarromero, S., Vermund, S., \& Gotuzzo, E. (2008).

Expansion of HIV and syphilis into the Peruvian Amazon: a survey of four communities of indigenous Amazonian ethnic group. International Journal of Infectious Diseases, 12(6), 89-94.

Crandon, L. (1986).

Medical dialogue and the political economy of medical pluralism: A case fron Rural Highland Bolivia. Medical Dialogue and the Political Economy of Medical Pluralism: A Case From Rural Highland Bolivia, 3, 463-476. 
Fassin, D. (2007).

When bodies remember: experiences and politics of AIDS in South Africa. California: University of California Press.

Farmer, P.; Castro, A. (2003)

El Sida y la violencia estructural: La culpabilización de la víctima. Buenos Aires: Cuadernos de antropología social v. 17 n.1

Good, B. J. (1994).

Medicine, rationaly and experience: an anthropological perspective. Cambridge: Cambridge University Press.

INEI. (2007).

II Censo de Comunidades Indígenas de la Amazonía Peruana 2007. Lima.

Kleinman, A. (1978).

What Kind of Model for the Anthropology of Medical Systems? American Anthropologist, $80(3), 661-665$.

Kleinman, A. (1978).

Culture, illness and care: clinical lessons from anthropologic and cross-cultural research. Annals of Internal Medicina, 88, 251-258.

Kleinman, A., \& Seeman, D. (2000).

The Personal Experience of Illness. In Handbook of Social Studies in Health and Medicine. London: SAGE Publications Ltd.

Mazin, R. (2011).

De lugares comunes a recomendaciones concretas: el VIH entre pueblos originariosypoblaciones indígenas del hemisferio occidental. Desacatos, 35, 87-94.

Menéndez, E. (2003).

Modelos de atención de los padecimientos: de exclusiones teóricas y articulaciones prácticas. Ciencia Y Salud Colectiva, 8(1), 185-207.

Minnich, E. (2005)

Transforming Knowledge. Philadelphia: Temple University Press

MINSA, \& DGE. (2013).

Análisis de la Situación Epidemiológica del VIH/SIDA en el Perú - 2013. Lima. Lima.

MINSA, INS, \& CNSI. (2009).

Plan General de la Estrategia Sanitaria Nacional. Salud de los Pueblos Indígenas 2009 - 2012. Lima.

MINSA, \& UNFPA. (2009).

Ucayali. Lima. 
Nuñez, G. (2011).

Hombres indígenas, diversidad sexual y vulnerabilidad al VIH-Sida: una exploración sobre las dificultades académicas para estudiar un tema emergente en la antropología. Desacatos, 35, 13-28.

ONUSIDA, \& OMS. (2005).

Situación de la epidemia de Sida : informe especial sobre la prevención del VIH.

Ormaeche, M., Whittembury, A., Pun, M., \& Suárez-Ognio, L. (2012).

Hepatitis B virus, syphilis, and HIV seroprevalence in pregnant women and male partners from six indigenous populations of the Peruvian Amazon 2007-2008. International Journal of Infectious Diseases, 16(10), 724-730.

Parker, R. (2014).

Sexuality, Culture and Power in HIV/AIDS Research. Annual Review of Anthropology, 30, 163-179.

Pintado, I. (2016). “

La implementación de políticas públicas en salud para los pueblos indígenas de Santa María de Nieva en Amazonas: la tensión entre la atención al VIH-SIDA y el enfoque intercultural. PUCP.

Pool, R., \& Wenzel, G. (2005).

Medical Anthropology. Understanding public health. UK: McGraw-Hill Education.

Portocarrero, J. (2015).

VIH en gestantes indígenas: un reto para la salud pública peruana. Revista Peruana de Medicina Experimental Y Salud Publica, 32(3), 546-54.

Portocarrero, J. (2016).

Percepciones sobre la vacunación de la rabia silvestre en población Awajún de la provincia de Condorcanqui, Amazonas. Physis: Revista de Saude Coletiva, 201-224.

Regan, J. (2010).

Los awajún y wampís contra el Estado: una reflexión sobre antropología política. Investigaciones Sociales, 14(24).

Surrallés. (2011).

Bagua 2009. Argumentos, 1.

UNICEF (2015).

Informe etnográfico para propuestas de modificatoria a la NTS de VIH y SIDA para población awajún de Condorcanqui - Amazonas - Agosto a Noviembre 2014. Lima.

Zavaleta, C. (2007).

High prevalence of HIV and syphilis in a remote native community of the Peruvian Amazon. The American Journal of Tropical Medicine and Hygiene, 76(4), 703-705.

Zavaleta, C., Mujica, J., Ypanaqué,P., \&Cueva, N.(2007).

Infecciones de transmisión sexual y VIH/SIDA en comunidades nativas de la Amazonía peruana: consideraciones culturales. Revista Peruana de Medicina Experimental Y Salud Publica, 24(3), 315-6. 